\title{
Acute bilirubin encephalopathy and its associated risk factors in a tertiary care hospital, Pakistan
}

\author{
Munir Ahmad', Abdur Rehman', \\ Mudasser Adnan ${ }^{3}$, Muhammad Khalil Surani ${ }^{4}$
}

\begin{abstract}
Objective: To determine the incidence of acute bilirubin encephalopathy (ABE) and its risk factors in neonates presenting with hyperbilirubinemia in a tertiary care children hospital.

Methods: This descriptive observational study was conducted from June 2018 to June 2019. A total of 300 infants who were admitted in neonatal ICU with diagnosis of hyperbilirubinemia in The Children's Hospital $\&$ The Institute of Child Health, Multan, Pakistan were included in this period. Incidence of ABE was noted. $A B E$ was divided into two categories on the basis of severity of symptoms; mild $A B E$ and moderate to severe $A B E$. Total serum bilirubin (TSB) in all neonates was measured in all patients in hospital laboratory using colorimetric method. ABO incompatibility and Rh factor incompatibility was also noted for each neonate.

Results: Out of 300 neonates who presented with hyperbilirubinemia, ABE was diagnosed in only $42(14.0 \%)$ neonates (mild ABE in $17(5.7 \%)$ and moderate in $25(8.3 \%)$. Out of 42 neonates of ABE, total serum bilirubin levels were $20-29.9 \mathrm{mg} / \mathrm{dL}$ in $24(40.5 \%)$ neonates, and $\geq 30 \mathrm{mg} / \mathrm{dL}$ in $18(42.8 \%)$ neonates. Pre-term birth was a significant risk factor of $A B E ; 23.8 \%$ in $A B E$ and $10.70 \%$ in non-ABE (p-value 0.01 ). During treatment, $02(4.76 \%)$ neonates expired due to $A B E$.

Conclusion: In present study, $A B E$ was diagnosed in $14.0 \%$ neonates who presented with hyperbilirubinemia. We found pre-term delivery as a significant risk factor of $A B E$.
\end{abstract}

KEYWORDS: Acute bilirubin encephalopathy, Hyperbilirubinemia, Pre-term birth, Mortality.

doi: https://doi.org/10.12669/pjms.36.6.2222

How to cite this:

Ahmad M, Rehman A, Adnan M, Surani MK. Acute bilirubin encephalopathy and its associated risk factors in a tertiary care hospital, Pakistan. Pak J Med Sci. 2020;36(6):1189-1192. doi: https://doi.org/10.12669/pjms.36.6.2222

This is an Open Access article distributed under the terms of the Creative Commons Attribution License (http://creativecommons.org/licenses/by/3.0), which permits unrestricted use, distribution, and reproduction in any medium, provided the original work is properly cited.

1. Dr. Munir Ahmad (FCPS Pediatric Medicine), Medical Officer Pediatric Medicine,

2. Dr. Abdur Rehman (FCPS Pediatric Medicine, FCPS Neonatology), Assistant Professor,

3. Dr. Mudasser Adnan (FCPS Pediatric Medicine), Senior Registrar Pediatric Medicine,

4. Dr. Muhammad Khalil Surani (FCPS Pediatric Medicine), Senior Registrar Pediatric Medicine,

1-4: The Children's Hospital \& The Institute of Child Health, Multan, Pakistan.

Correspondence:

Dr. Munir Ahmad,

Mohalla Nasir Abad Street No. 7,

House No. 2241/160, Mumtazabad Colony,

Multan, Pakistan.

Email: dr.munir.ahmad2@gmail.com

* Received for Publication:

January 12, 2020

* $1^{\text {st }}$ Revision Received:

* $2^{\text {nd }}$ Revision Received:

* $3^{\text {rd }}$ Revision Received:

* Final Revision Accepted:

February 13, 2020

May 29, 2020

July 8, 2020

July 15, 2020

\section{INTRODUCTION}

Hyperbilirubinemia is very common in early neonatal period. Bilirubin levels rise for first few days of life and then return to normal up to the end of first week of life. ${ }^{1}$ In few neonates' bilirubin levels rise to such a high level that these crosses the blood brain barrier and results in acute bilirubin encephalopathy (ABE). ${ }^{2} \mathrm{ABE}$ is a group of clinical/pathologic abnormalities that results from bilirubin toxicity in central nervous system (CNS). According to American academy of pediatrics (APP) $\mathrm{ABE}$ is an acute manifestation seen in the first week of life after birth. ${ }^{3} \mathrm{ABE}$ is one of the highly prevalent diseases of neonates and is a major cause of hearing impairment, developmental delay and cerebral palsy especially in developing countries., ${ }^{4,5} \mathrm{ABE}$ is 
associated with $5 \%$ to $14 \%$ higher risk of deaths and 2 to 3 folds' higher risk of neurological defects in neonates who survive from ABE. ${ }^{6} \mathrm{ABE}$ has three phases, disease is reversible in first phase, but there is $2^{\text {nd }}$ and $3^{\text {rd }}$ phase is associated with higher risk of kernicterus (due to chronic bilirubin encephalopathy (CBE). ${ }^{7}$

Risk factors of $\mathrm{ABE}$ varies from region to region, such as male gender, rhesus iso-immunisation and gestational age 35-38 years are common factors in Europe. ${ }^{8}$ A systemic review conducted in developing countries including Pakistan reported sepsis, G6PD deficiency, rhesus iso-immunisation, and low birth weight and small gestational age as common factors leading to ABE. ${ }^{9}$

The exact incidence of $\mathrm{ABE}$ is not available for developing countries because of delays in diagnosis, flaws in reporting, and absence of database management systems for collection of disease information. ${ }^{5}$ A study from Baghdad reported $\mathrm{ABE}$ in 1749 neonates per 100,000 live births. ${ }^{10}$ In Pakistan, data regarding ABE is very scarce. So we aimed to determine the incidence of $\mathrm{ABE}$ and its risk factors in neonates presenting with hyperbilirubinemia in a tertiary care child hospital.

\section{METHODS}

This descriptive observational study was conducted from June 2018 to June 2019. A total of 300 infants who were admitted in neonatal ICU with diagnosis of hyperbilirubinemia in The Children's Hospital \& The Institute of Child Health, Multan were studied in this period. Approval from ethical committee of the hospital was taken (EC No: 62, Dated: 20-01-2020).

Incidence of $\mathrm{ABE}$ was noted. $\mathrm{ABE}$ was divided into two categories on the basis of severity; mild $A B E$; presence of poor feeding, lethargy, hypo/ hyper-tonia, or high pitch crying voice. Moderate to Severe $A B E$; presence of retro-collis, rigidity or flaccidity, opisthotonus, paralysis of upward gaze, apnea, or seizures. Mortality due to ABE was also noted.

Total serum bilirubin (TSB) in all neonates was measured in all patients in hospital laboratory using colorimetric method. ABO incompatibility and $\mathrm{Rh}$ factor incompatibility was also done for each neonate diagnosed with encephalopathy. $\mathrm{ABE}$ due to hemolytic anemia was diagnosed if TSB level $\geq 20 \mathrm{mg} / \mathrm{dl}$ and hematocrit (HCT) $\leq 35 \%$ in neonate.
After confirming the diagnosis of $\mathrm{ABE}$, the $A B E$ infants were categorized into two categories depending upon the TSB levels; TSB 20-29.9 mg/ $\mathrm{dL}$ were labelled as at threshold of intervention, while those having $\geq 30 \mathrm{mg} / \mathrm{dL}$, at high risk of development of kernicterus. Risk factors of $\mathrm{ABE}$ such as preterm delivery, place of delivery, $\mathrm{ABO} /$ $\mathrm{Rh}$ incompatibility were noted. For data analysis we used SPSS v23 software. Risk factors of ABE, in $\mathrm{ABE}$ and non-ABE neonates were compared using chi-square test. P-value $\leq 0.05$ was taken as significant.

\section{RESULTS}

Out of 300 neonates who presented with hyperbilirubinemia, ABE was diagnosed in only $42(14.0 \%)$ neonates (mild ABE in $17(5.7 \%)$ and moderate to severe in $25(8.3 \%)$. Out of 42 neonates of ABE, TSB levels were $20-29.9 \mathrm{mg} / \mathrm{dL}$ in $21(50.0 \%)$ neonates, $\geq 30 \mathrm{mg} / \mathrm{dL}$ in $04(9.5 \%)$ neonates, while $<20$ in $17(40.5 \%)$ neonates. During treatment, $02(4.76 \%)$ neonates expired due to ABE (Table-I).

Regarding risk factors of $\mathrm{ABE}$, there were 10 $(23.8 \%)$ preterm neonates in ABE neonates, and $26(10.70 \%)$ preterm neonates in non-ABE group (p-value 0.01). There was no significant difference in place of birth and birth weight between the groups. There was no significant difference in $\mathrm{ABO}$ and Rh incompatibility between the $\mathrm{ABE}$ and non-ABE neonates. (Table-II).

\section{DISCUSSION}

$\mathrm{ABE}$ is still a problem in developing countries. The American National quality forum has defined death or disability (kernicterus) as a very serious event that results from failure of early diagnosis or failure to treat hyperbilirubinemia and stressed that kernicterus should become a "never event" in the world. ${ }^{11}$ However, in poor countries due

Table-I: ABE Major Characteristics and Outcomes.

\begin{tabular}{lc}
\hline Total ABE & $42(14.0 \%)$ \\
ABE Severity & \\
Mild ABE & $17(5.7 \%)$ \\
Moderate to severe ABE & $25(8.3 \%)$ \\
Total Serum Bilirubin levels in ABE infants. \\
TSB $<20 \mathrm{mg} / \mathrm{dL}$ & $17(40.5 \%)$ \\
TSB $20-29.9 \mathrm{mg} / \mathrm{dL}$ & $21(50.0 \%)$ \\
TSB $>30 \mathrm{mg} / \mathrm{dL}$ & $04(9.5 \%)$ \\
Mortality & $2(4.76 \%)$ \\
\hline
\end{tabular}

Vol. 36 No. $6 \quad$ www.pjms.org.pk 1190 
Table-II: Risk Factors Associated with ABE.

\begin{tabular}{lccc}
\hline & $A B E(N=42)$ & Non-ABE $(n=258)$ & $p$-value \\
\hline $\begin{array}{l}\text { Pre-term Birth } \\
\text { Place of Birth }\end{array}$ & $10(23.8 \%)$ & $26(10.7 \%)$ & 0.01 \\
$\quad$ Hospital & $13(30.9 \%)$ & $115(44.6 \%)$ & 0.09 \\
$\quad$ Clinic & $29(69.1 \%)$ & $143(55.4 \%)$ & 0.41 \\
Birth Weight & & & \\
$\quad<1500$ grams & $02(4.7 \%)$ & $08(3.10 \%)$ & $113(43.8 \%)$ \\
$\quad 1500-2499$ grams & $14(33.3 \%)$ & $137(53.1 \%)$ & 0.75 \\
$\quad>2500$ grams & $26(62.0 \%)$ & & 0.40 \\
Other Hematologic Causes of Hyperbilirubinemia & $12(28.6 \%)$ & $14(17.5 \%)$ & \\
$\quad$ ABO Incompatibility & $1(2.4 \%)$ & & \\
Rh Factor Incompatibility & & & \\
\hline
\end{tabular}

to the availability of limited resources and proper neonatal facilities has posed a major challenge for making Kernicterus a never event. Many of the neonates of hyperbilirubinemia in developing nations present late in hospital after development of symptoms of ABE. Many studies have reported higher incidence of $\mathrm{ABE}$ among neonates who are born in out-hospital facilities. ${ }^{12-14}$

Some studies have reported a direct association between TSB and risk of ABE. Iskander et al. and Kuzniewicz et al. reported that the risk of $\mathrm{ABE}$ is lower in neonates having TSB $<30 \mathrm{mg} / \mathrm{dL} \cdot{ }^{15,16}$ While a study by Ogunlesi et al. reported ABE in $38.26 \%$ neonates having TBS $<20 \mathrm{mg} / \mathrm{dl}$, some of these neonates were suffering from sepsis or were pre-term. ${ }^{17}$ In present study there were $40.5 \%$ neonates having TSB $<20 \mathrm{mg} / \mathrm{dL}$, there were only $9.5 \%$ neonates having TSB $\geq 30 \mathrm{mg} / \mathrm{dL}$.

Studies have also reported that place of birth also effects the risk of $\mathrm{ABE}$. In out-of-hospital birth places there is a poor knowledge regarding hyperbilirubinemia and its treatment options. ${ }^{18,19}$ A study conducted by Diala et al. reported a strong association between the in home delivery and frequency of ABE..$^{18}$ In our study, there was no case of home birth and we did not find any significant difference in incidence of $\mathrm{ABE}$ in clinic birth and in-hospital birth neonates. A study from Pakistan by Korejo et al. reported home delivery and late presentation as risk factors of kernicterus in hyperbilirubinemia neonates. ${ }^{20}$

In present study, we found pre-term delivery as a significant risk factors of $\mathrm{ABE}$. We found preterm birth in $23.8 \%$ neonates in $\mathrm{ABE}$ neonates and in $10.70 \%$ neonates in non-ABE neonates. A study conducted in Myanmar by Arnolda et al. also reported opposite results. In their study preterm birth rate was $8.3-9.4 \%$ in $\mathrm{ABE}$ neonates versus $16.1-30.3 \%$ in non- $\mathrm{ABE}$ neonates. ${ }^{21} \mathrm{~A}$ recent review by Bhutani et al., concluded that pre-term neonates are at increased risk of progression to $\mathrm{ABE}$ and more likely to develop long term neurological complications either due to $\mathrm{ABE}$ or due to overtreatment of phototherapy or exchange transfusion. ${ }^{22}$

We did not find any significant difference in $\mathrm{ABO}$ incompatibility and $\mathrm{Rh}$ incompatibility. Arnolda et al. also reported similar findings. ${ }^{20}$ Whoever a study by Bhutani et al. reported that $\mathrm{Rh}$ incompatibility is responsible for nearly $1 / 3^{\text {rd }}$ all incidences of ABE. ${ }^{5}$

Significance of study: Our study is one of the few studies conducted in Pakistan that have determined the risk factors of development of ABE in neonatal hyperbilirubinemia. Identification of risk factors can help in determining the high risk hyperbilirubinemia neonates in whom ABE can occur.

Limitations of the study: It's a single center study and we only included the neonates who presented with hyperbilirubinemia. Moreover, our hospital is situated in a dense urban population area. So this study cannot determine the true incidence of ABE. Because most of population of Pakistan nearly $70 \%$ belongs to rural areas and many births occur in basic health facilities or sometimes at home. So there is a need to conduct multi-center study to determine the exact incidence of ABE in our population and to determine the risk factors associated with $\mathrm{ABE}$. 


\section{CONCLUSION}

In present study, $\mathrm{ABE}$ was diagnosed in $14.0 \%$ neonates who presented with hyperbilirubinemia. We found pre-term delivery as a significant risk factor of ABE.

\section{REFERENCES}

1. Bech LF, Donneborg ML, Lund AM, Ebbesen F. Extreme neonatal hyperbilirubinemia, acute bilirubin encephalopathy, and kernicterus spectrum disorder in children with galactosemia. Pediatr Res. 2018;84(2):228-232. doi: 10.1038/s41390-018-0066-0

2. Usman F, Diala UM, Shapiro SM, Le Pichon JB, Slusher TM. Acute bilirubin encephalopathy and its progression to kernicterus: current perspectives. Res Rep Neonatol. 2018:8:33-44. doi: 10.2147/RRN.S125758

3. Kaplan M, Hammerman C. American Academy of Pediatrics guidelines for detecting neonatal hyperbilirubinaemia and preventing kernicterus. Arch Dis Child Fetal Neonatal Ed. 2005;90(6):F448-F449. doi: 10.1136/adc.2004.068726

4. Olusanya B, Osibanjo F, Mabogunje C, Slusher TM, Olowe $\mathrm{S}$. The burden and management of neonatal jaundice in Nigeria: A scoping review of the literature. Niger J Clin Pract. 2016;19(1):1-17. doi: 10.4103/1119-3077.173703

5. Bhutani VK, Zipursky A, Blencowe $H$, Khanna $\mathrm{R}$, Sgro M, Ebbesen F, et al. Neonatal hyperbilirubinemia and Rhesus disease of the newborn: incidence and impairment estimates for 2010 at regional and global levels. Pediatr Res. 2013;74(Suppl 1):86-100. doi: $10.1038 /$ pr.2013.208

6. Das S, van Landeghem FKH. Clinicopathological Spectrum of Bilirubin Encephalopathy/Kernicterus. Diagnostics (Basel). 2019;9(1):24. doi: 10.3390/diagnostics9010024

7. Burke B, Robbins J, Hobbs C. American Academy of Pediatrics Subcommittee on Hyperbilirubinemia Management of hyperbilirubinemia in the newborn infant 35 or more weeks of gestation. Pediatrics. 2004;114(1):297316. doi: 10.1542 / peds.114.1.297

8. Alken J, Hakansson S, Ekeus C, Gustafson P, Norman M. Rates of extreme neonatal hyperbilirubinemia and kernicterus in children and adherence to national guidelines for screening, diagnosis, and treatment in Sweden. JAMA Netw Open. 2019;2(3):e190858. doi: 10.1001/jamanetworkopen.2019.0858

9. Olusanya BO, Osibanjo FB, Slusher TM. Risk factors for severe neonatal hyperbilirubinemia in low and middleincome countries: a systematic review and meta-analysis. PLoS One. 2015;10(2):e0117229. doi: 10.1371/journal. pone. 0117229

10. Hameed NN, Vilms R, Bhutani VK. Severe neonatal hyperbilirubinemia and adverse short-term consequences in Baghdad, Iraq. Neonatology. 2011;100(1):57-63. doi: $10.1159 / 000321990$
11. Forum NQ. Serious reportable events in healthcare-2011 update: A consensus report. 2011.

12. Adebami OJ. Factors associated with the incidence of acute bilirubin encephalopathy in Nigerian population. J Pediatr Neurol. 2011;9(03):347-353. doi: 10.3233/JPN-2011-0485

13. Eneh A, Oruamabo R. Neonatal jaundice in a special care baby unit (SCBU) in Port Harcourt, Nigeria: A prospective study. Port Harcourt Med J. 2008;2(2):110-117.

14. Owa JA, Ogunlesi TA. Why we are still doing so many exchange blood transfusion for neonatal jaundice in Nigeria. World J Pediatr. 2009;5(1):51-55. doi: 10.1007/s12519-0090009-2

15. Iskander I, Gamaleldin R, El Houchi S, El Shenawy A, Seoud I, El Gharbawi N, et al. Serum bilirubin and bilirubin/albumin ratio as predictors of bilirubin encephalopathy. Pediatrics. 2014;134(5):e1330-e1339. doi: 10.1542/peds.2013-1764

16. Kuzniewicz MW, Wickremasinghe AC, Wu YW, McCulloch CE, Walsh EM, Wi S, et al. Incidence, etiology, and outcomes of hazardous hyperbilirubinemia in newborns. Pediatrics. 2014;134(3):504-509. doi: 10.1542/ peds.2014-0987

17. Ogunlesi TA, IOF D, Adekanmbi A. The incidence and outcome of bilirubin encephalopathy in Nigeria: A bi-centre study. Niger J Med. 2007;16(4):354-359.

18. Diala UM, Wennberg RP, Abdulkadir I, Farouk ZL, Zabetta CDC, Omoyibo E, et al. Patterns of acute bilirubin encephalopathy in Nigeria: A multicenter pre-intervention study. J Perinatol. 2018;38(7):873-880. doi: 10.1038/s41372018-0094-y

19. Ogunlesi T, Abdul A. Maternal knowledge and care Seeking behaviors for newborn jaundice in Sagamu, Southwest Nigeria. Niger J Clin Pract. 2015;18(1):33-40. doi: 10.4103/1119-3077.146976

20. Korejo HB, Bhurgri GR, Bhand S, Qureshi MA, Dahri GM, Chohan RK. Risk factors for kernicterus in neonatal jaundice. Gomal J Med Sci. 2010;8(1):12-15.

21. Arnolda G, Nwe H, Trevisanuto D, Thin A, Thein A, Defechereux $\mathrm{T}$, et al. Risk factors for acute bilirubin encephalopathy on admission to two Myanmar national paediatric hospitals. Matern Health Neonatol Perinatol. 2015;1:22. doi: 10.1186/s40748-015-0024-3

22. Bhutani VK, Wong RJ, Stevenson DK. Hyperbilirubinemia in Preterm Neonates. Clin Perinatol. 2016;43(2):215-232. doi: 10.1016/j.clp.2016.01.001

\section{Authors Contribution:}

MA: Conceived, designed the research methodology and is responsible for integrity of study.

AR: Supervised the research project, did editing. MA \& MKS: helped in data collection and compilation. 